\title{
Correction to: "Predictors of progression in autosomal dominant and autosomal recessive polycystic kidney disease"
}

\author{
Eric G. Benz ${ }^{1,2}$ - Erum A. Hartung ${ }^{1,2}$ \\ Published online: 23 June 2021 \\ (C) IPNA 2021
}

\section{Correction to: Pediatr Nephrol}

https://doi.org/10.1007/s00467-020-04869-w

The original version of this article unfortunately contained a mistake. During the process of typesetting, corrections to the labels of Figs. 1, 2, and 3 were not carried out accurately. The publisher apologizes for this mistake. Below, the figures with the correct labels and in the correct order are presented below. The corrections were also made in the original article.

Erum A. Hartung

hartunge@email.chop.edu

1 Division of Nephrology, Children's Hospital of Philadelphia, 3401

Civic Center Boulevard, Philadelphia, PA 19104, USA

2 Department of Pediatrics, Perelman School of Medicine of the University of Pennsylvania, Philadelphia, PA, USA 
Fig. 1 Differences in kidney survival between individuals with PKD1 truncating mutations, PKD1 non-truncating mutations, and PKD2 mutations (figure adapted from Cornec-Le Gall et al. [1], used with permission)

Fig. 2 Mayo Clinic imaging classification to predict risk of GFR decline in patients with ADPKD. a Subclassification of patients with typical (class 1) ADPKD into subclasses 1A through 1E, based on baseline height-adjusted total kidney volume (HtTKV) for patient age. b Predicted GFR slopes for males with ADPKD subclasses $1 \mathrm{~A}$ through 1E (figure reproduced from Irazabal et al. [2], used with permission)
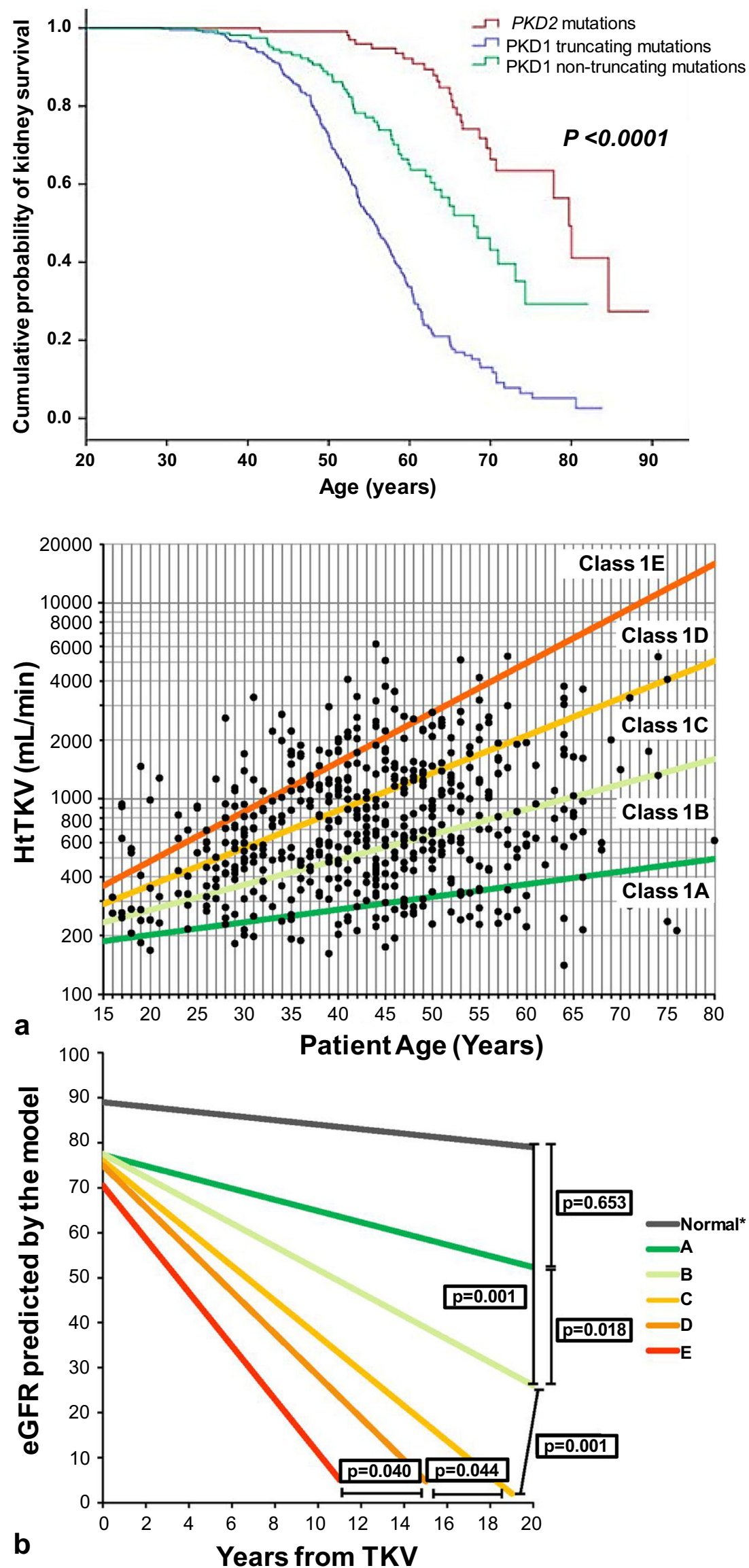


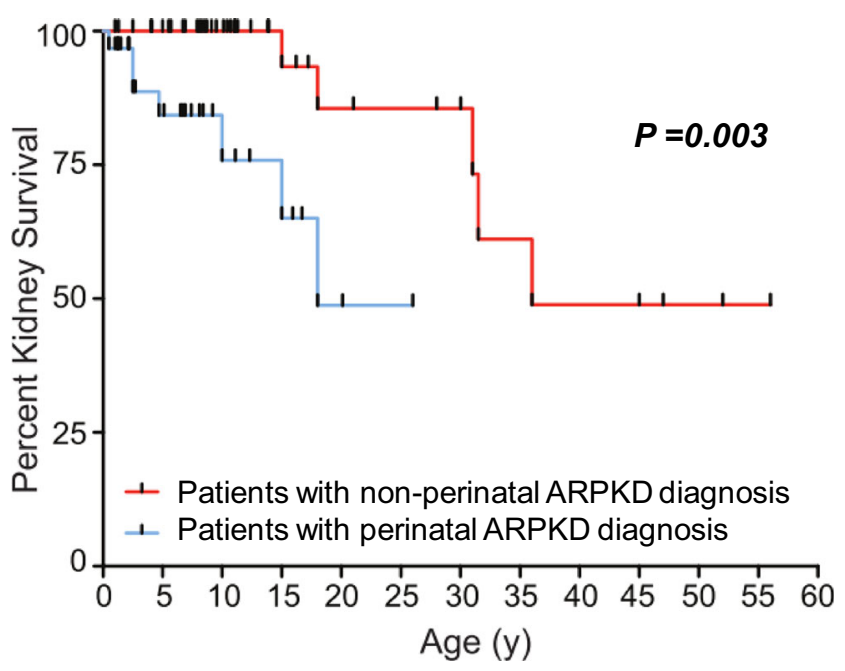

Fig. 3 Kidney survival in individuals diagnosed with ARPKD in the perinatal period (age $<30$ days) compared with those diagnosed after the perinatal period (figure reproduced from Gunay-Aygun et al. [3], used with permission)

\section{References}

1. Cornec-Le Gall E, Audrézet M-P, Chen J-M, Hourmant M, Morin M-P, Perrichot R, Charasse C, Whebe B, Renaudineau E, Jousset P,
Guillodo M-P, Grall-Jezequel A, Saliou P, Férec C, Le Meur Y (2013) Type of PKD1 mutation influences renal outcome in ADPKD. J Am Soc Nephrol 24:1006-1013. https://doi.org/10. 1681/ASN.2012070650

2. Irazabal MV, Rangel LJ, Bergstralh EJ, Osborn SL, Harmon AJ, Sundsbak JL, Bae KT, Chapman AB, Grantham JJ, Mrug M, Hogan MC, El-Zoghby ZM, Harris PC, Erickson BJ, King BF, Torres VE (2015) Imaging classification of autosomal dominant polycystic kidney disease: a simple model for selecting patients for clinical trials. J Am Soc Nephrol 26:160-172. https://doi.org/10. 1681/ASN.2013101138

3. Gunay-Aygun M, Font-Montgomery E, Lukose L, Tuchman M, Graf J, Bryant JC, Kleta R, Garcia A, Edwards H, Piwnica-Worms K, Adams D, Bernardini I, Fischer RE, Krasnewich D, Oden N, Ling A, Quezado Z, Zak C, Daryanani KT, Turkbey B, Choyke P, GuayWoodford LM, Gahl WA (2010) Correlation of kidney function, volume and imaging findings, and PKHD1 mutations in 73 patients with autosomal recessive polycystic kidney disease. Clin J Am Soc Nephrol 5:972-984. https://doi.org/10.2215/CJN.07141009

Publisher's note Springer Nature remains neutral with regard to jurisdictional claims in published maps and institutional affiliations. 